\title{
Uma análise de um grupo de ouvidores de vozes enquanto movimento social e potência política
}

\author{
An analysis of a hearing voices group as a social movement and \\ political power \\ Juliana Valeri Simão Trevisan', Daiana Paula Milani Baroni1
}

DOI: 10.1590/0103-11042020E308

RESUMO Os grupos de ouvidores de vozes surgiram, nos anos 1980, da tentativa de aproximar pessoas com experiências de audição de vozes interessadas em compartilhar suas histórias, dificuldades e estratégias de enfrentamento, na contramão da patologização dessa experiência. O intuito seria promover apoio mútuo e novas compreensões em relação ao fenômeno. O objetivo deste artigo foi trazer algumas considerações a respeito do processo de construção e dinâmica de um grupo de ouvidores de vozes no Brasil a partir das diretrizes do Movimento Intervoice, analisando suas potencialidades enquanto movimento social e político. A metodologia utilizada trata-se de revisão bibliográfica e observação participante. Como resultado da pesquisa, pôde-se observar indícios da importância desse tipo de grupo como potencialidade política e arena para mobilização social, em uma perspectiva micropolítica, uma vez que suas práticas se guiam por meio de princípios, como o empoderamento dos participantes, o protagonismo, a autonomia e a busca por cidadania.

PALAVRAS-CHAVE Psicologia social. Saúde mental. Recovery.

\begin{abstract}
The hearing voices groups arose, in the 1980s, from the attempt to bring together people with experiences of hearing voices interested in sharing their stories, difficulties and coping strategies, against the pathologization of this experience. The aim would be to promote mutual support and new understandings regarding the phenomenon. The objective of this article was to bring some considerations about the process of construction and dynamics of a group of voices hearers in Brazil from the guidelines of the Intervoice Movement, analyzing its potentialities as a social and political movement. The methodology used is bibliographic review and participant observation. As a result of the research, it was possible to observe evidence of the importance of this type of group as a political potential and arena for social mobilization, in a micropolitical perspective, since their practices are guided by principles, such as the empowerment of the participants, the protagonism, autonomy and the search for citizenship.
\end{abstract}

KEYWORDS Social psychology. Mental health. Recovery.

1 Universidade Federal de São João del-Rei (UFSJ)

- São João del-Rei (MG),

Brasil.

jvstrevisan@gmail.com 


\section{Introdução}

Este artigo busca desenvolver algumas reflexões a partir da experiência de um grupo de ouvidores de vozes, criado no ano de 2017 , em um contexto universitário, envolvendo profissionais da área da saúde, alunos dos cursos de Psicologia e Medicina e ouvidores de vozes interessados em abordar em primeira pessoa a experiência com e sobre as vozes. $\mathrm{O}$ projeto do grupo em questão se vincula ao Movimento Internacional Intervoice, nascido na Holanda na década de 1980, e oficialmente estabelecido no Brasil no ano de 2015. Os grupos de ouvidores de vozes são espaços de diálogo e trocas de experiências no intuito de ressignificar a audição de vozes, incentivar o trabalho de diálogo e controle em relação às vozes e o enfrentamento das consequências oriundas dessa experiência ${ }^{1}$. Cabe ressaltar a existência anterior de outras práticas coletivas direcionadas a sujeitos ouvidores de vozes no Brasil; no entanto, até 2015, desvinculadas oficialmente das diretrizes e referências de pesquisa e ações do Movimento Intervoice.

No presente artigo, elegemos, como tema principal a ser desenvolvido em torno da problemática da experiência das vozes, as ações coletivas no contexto grupal que possam apontar para uma das principais direções do Movimento Intervoice, a saber, a criação de um contexto propício para integração de forças e saberes em prol do empoderamento dos sujeitos participantes. Tal temática se desprende de reflexões e proposições do próprio Movimento Internacional Intervoice que compreende sua existência vinculada à produção de posicionamentos diversos diante do fato da escuta de vozes e consequentes efeitos em nível singular e coletivo/social para os próprios sujeitos em questão' ${ }^{1}$ Enfocaremos, portanto, as possibilidades de emergência de ações que venham a germinar ou estabelecer uma articulação grupal rumo à consolidação de um movimento social e/ou posicionamento político que conduza os participantes a outras perspectivas e visibilidades em relação às suas condições de ouvidores.
A seguir, apresentaremos, de forma breve, parte do processo histórico que culminou na possibilidade de criação de um espaço de debate e de ações em saúde mental a partir do Movimento da Luta Antimanicomial e da Reforma Psiquiátrica; e, assim, buscar conexões com as bases teóricas e diretrizes do Movimento Intervoice e com as ações de um grupo específico de ouvidores de vozes no Brasil. Buscaremos frisar, nessa aproximação, a importância da formação de grupos no processo emancipatório de seus participantes, no trabalho de busca por soluções, no atendimento das reais necessidades dos envolvidos e no reposicionamento social.

\section{Movimento social, Luta Antimanicomial e Intervoice: algumas conexões}

Existem diversas teorias que abordam, embasam e buscam explicar movimentos sociais. Segundo Gohn², há as que são construídas a partir do eixo cultural e dizem respeito à construção identitária com base nas reflexões dos indivíduos que compõem os grupos; as que focam o eixo de justiça social por meio da exposição de questões de desigualdades e redistribuição para compensar injustiças históricas; e as que enfatizam a autonomia e as resistência dos movimentos sociais; além de teorias que dão atenção para o processo de institucionalização das ações coletivas.

Para Melucci, citado por Lüchmann e Rodrigues $^{3}$, os movimentos sociais anunciam uma mudança para o presente. Para os autores, inicialmente,

os movimentos sociais são ações coletivas de caráter fragmentário e heterogêneo que destinam boa parte de suas energias e recursos para o gerenciamento de sua complexidade ${ }^{3(400)}[\mathrm{e}]$

[...] são redes de ações que desenham uma estrutura submersa, um mosaico formado por indivíduos e grupos que, em estado de latência, gestionam, no cotidiano, as lutas, reflexões e os questionamentos acerca da realidade social3(401) 
O movimento de Reforma Psiquiátrica no Brasil teve início entre os anos de 1978 e 1980, destacando a atuação do Movimento dos Trabalhadores em Saúde Mental (MTSM). O estopim para o movimento da reforma e o principal agente para a formação do MTSM pode ter sido a 'crise da Dinsam' (Divisão Nacional de Saúde Mental), órgão do Ministério da Saúde que realizava a formulação de políticas relativas à saúde mental ${ }^{4}$.

O MTSM buscou constituir um espaço de luta não institucional, promovendo debates e encaminhamentos para a transformação da realidade psiquiátrica, tomando como pauta inicialmente a regularização das condições trabalhistas, a crítica aos manicômios e ao uso de eletrochoque, tendo em vista a humanização do tratamento. Durante o ano de 1978, foram produzidos diversos documentos com reivindicações do movimento que traziam críticas ao autoritarismo dentro das instituições, entre outros aspectos relacionados com a busca por um tratamento mais humanizado para os usuários do serviço de saúde mental, bem como para os trabalhadores da área ${ }^{4}$.

Nos anos seguintes, foram realizados congressos e encontros de trabalhadores em saúde mental, em que se discutiram aspectos relativos ao modelo asilar dos hospitais psiquiátricos, políticas nacionais de saúde mental e defesa dos direitos humanos dos pacientes, tendo como destaque o II Congresso Nacional dos Trabalhadores de Saúde Mental, realizado em Bauru (SP) em 1987, no qual despontou efetivamente o Movimento Nacional da Luta Antimanicomial, com o lema 'Por uma sociedade sem manicômios', exigindo que os hospícios fossem substituídos por outros espaços de tratamento que garantissem dignidade, liberdade e os direitos dos usuários do serviço ${ }^{5}$.

Franco Basaglia inspirou muitas das ações do Movimento da Luta Antimaniconial no Brasil. Basaglia (1974), citado por Severo e Dimenstein $^{6}$, afirma que a ideia de doença mental é uma legitimação do saber biomédico diante da experiência da loucura, compreendendo a psiquiatria como perpetuadora do que o autor chama de 'violência global'. O diagnóstico seria assim uma ferramenta para eternizar a lógica de exclusão de seres humanos que apresentassem vivências não enquadradas na norma social, como nos apontam as autoras:

A condição de exclusão nessa sociedade é demarcada pelo consumo ou não dessas formas de vida padronizadas. A relação da sociedade com a loucura, bem como do louco consigo mesmo, são atravessadas pelos modos de exclusão vigentes na contemporaneidade ${ }^{6(61)}$.

O Movimento da Luta Antimanicomial pode ser considerado movimento social uma vez que busca a reapropriação da autonomia e da identidade do sujeito, amputadas pela opressão e manipulação do sistema ${ }^{3}$; assim como a busca por integração ao invés da exclusão a que foram condenados por décadas sujeitos diagnosticados como loucos. No entanto, o Movimento da Luta Antimanicomial difere de outros movimentos sociais no Brasil por ter seu início a partir da mobilização de profissionais que trabalhavam na área de saúde mental, e não a partir dos próprios pacientes internados nos hospitais psiquiátricos ${ }^{5}$.

Assim como o Movimento da Luta Antimanicomial, o Movimento da Rede Internacional Intervoice teve seu início atrelado à mobilização dos profissionais, envolvendo, concomitantemente, os ouvidores. Após cerca de 40 anos de sua formação, a Rede Intervoice já estava presente em mais de 30 países, somando 450 grupos que estruturam suas práticas, sobretudo, a partir da ideia de que audição de vozes não é sinônimo de patologia, estando tal experiência, muitas vezes, ligada a traumas e a situações vivenciadas pelo próprio ouvidor. De acordo com a perspectiva do Intervoice, é necessário que tais situações de base para a experiência de audição de vozes possam ser identificadas e elaboradas pelos ouvidores, estabelecendo assim uma nova forma de relação com as vozes, mais amigável e de maior controle sobre o fenômeno ${ }^{7}$. O entendimento de que é possível conviver com as vozes e dar prosseguimento à vidaé elementar para que os ouvidores não passem apenas pelo viés da medicalização, 
tendo grande possibilidade de superação das consequências danosas dessa experiência.

Os Grupos de Ouvidores de Vozes pautados pela ideia de auto e mútua ajuda compartilham de certos aspectos propostos pelo movimento em saúde mental brasileiro que tem como objetivo interferir e mudar as políticas, os serviços, a legislação, a cultura profissional e a cultura popular relativas à doença e à saúde mental8. No entanto, algumas ações e perspectivas podem variar de um grupo brasileiro para um grupo em outro país, tendo em vista as diferenças culturais; de acesso a serviços de saúde e a informações; e conforme o próprio processo em que nos encontramos enquanto país com um histórico de subordinação cultural e tecnológica.

De acordo com Vasconcelos ${ }^{8}$, existem inúmeras diferenças em relação à dinâmica e à formação de movimentos sociais entre países da divisão socioeconômica do Norte e Sul globais em decorrência das conformações históricas e sociais. Essa construção traria, assim, implicações no âmbito da saúde mental e no modo que a população concebe o cuidado e se relaciona com o saber biomédico, trazendo como características: a dependência do usuário reconhecida e, muitas vezes, estimulada (autonomia e independência pessoal não valorizadas); as organizações dos usuários estando em dependência do Estado ou de organizações não governamentais; a primazia da cultura terapêutica que centraliza o tratamento e os profissionais ao invés do usuário; a condição muito recente dos serviços de atenção psicossocial como contexto de surgimento de possibilidades de organização de movimentos.

\section{A Rede Internacional Intervoice e o Grupo de Ouvidores de Vozes}

A Rede Internacional Intervoice - The International Network for Training, Education and Research into Hearing Voices - surgiu em 1980, na Holanda, a partir da inquietação trazida por Patsy Hage ao seu psiquiatra Marius Romme, que não considerava as vozes ouvidas por Hage como reais' ${ }^{1}$. Em decorrência desse processo de indagação, Romme e a Dra.
Escher passam a estruturar ações conjuntas com Patsy e demais ouvidores de vozes, no intuito de dar visibilidade a relatos sobre a experiência de ouvir vozes, ao invés de calá-las como sintomas de uma doença.

Juntos, paciente e médico, foram a um programa da televisão holandesa em busca de outras pessoas que também estivessem passando pela experiência de Patsy. Ao solicitar o contato de demais ouvidores, mais de 700 pessoas se manifestaram; e 450 decidiram se encontrar com Romme para serem entrevistadas. Destas 450 pessoas, 150 relataram viver bem com suas vozes, sem a necessidade de tratamento químico ou apoio psicológico ${ }^{1}$. Romme então pôde observar que as pessoas que relatavam conviver bem com as suas vozes não as 'patologizavam', seguindo suas vidas sem as consequências advindas do recebimento de um diagnóstico psiquiátrico, sobretudo o de esquizofrenia.

Surgem, desse modo, os grupos de ouvidores de vozes guiados pelas diretrizes do Intervoice, consolidando-se por meio da aproximação de pessoas com experiências de audição de vozes dispostas a compartilhar suas histórias, dificuldades e estratégias de enfrentamento das vozes. Nos grupos, o discurso sobre as vozes deve partir do próprio sujeito ouvidor - protagonista dessa experiência, que será finalmente ouvido e respeitado -, adquirindo visibilidade e, por consequência, o poder de interferir na forma por meio do qual ouvidores, profissionais e sociedade observam o fenômeno. Trata-se de grupos de auto e mútua ajuda, com o objetivo fazer com que ouvidores, em meio a seus pares, fortaleçam-se e se apoiem, criando formas de se conceber e tratar tal experiência, para além do engessamento em uma ideia formal de adoecimento psíquico irreversível.

A Rede Internacional Intervoice segue certas diretrizes fundamentais para que não haja discriminação e/ou hierarquias nos grupos, incentivando narrativas em primeira pessoa em detrimento de pareceres especializados e disponibilizando materiais e conteúdos informativos para que facilitadores possam criar e conduzir os grupos a partir 
de tais valores, além de buscar desmistificar socialmente as vozes. Portanto, os grupos estabelecidos a partir das diretrizes do Intervoice apresentam como seus pilares: o modelo de auto e mútua ajuda (tratando-se de um espaço para os pares buscarem apoio entre si); acolhimento das diversidades subjetivas e das explicações e crenças sobre as vozes e suas origens; a não suposição de doenças entre si e não prevalência do saber médico ou psicológico em detrimento do saber da experiência do próprio sujeito ouvidor; a flexibilidade quanto aos assuntos discutidos (nem sempre os relatos estarão inteiramente baseados na experiência das vozes); e a centralidade das práticas nos ouvidores e em suas experiências?.

O Movimento Intervoice chegou oficialmente ao Brasil em 2015, após a visita de seu atual diretor Paul Baker, realizando palestras no intuito de estender a rede. Desde então, grupos passaram a ser formados em cidades como Rio de Janeiro, Ribeirão Preto, Campinas e Brasília, aproximando ouvidores na discussão em relação às suas próprias condições e seus lugares na sociedade. Anteriormente à chegada de Baker e da solidificação das diretrizes do Intervoice no Brasil, já havia iniciativas que buscavam o acolhimento dos ouvidores e de suas vozes. É o caso da 'Oficina de Vozes', criada em 1998 por Octavio Domont de Serpa Júnior no Hospital Casa Verde, também a partir da queixa de um ouvidor que dizia não ter espaço para falar de suas vozes. Posteriormente, e em parceria com Núria Malajovich Muñoz e Erotildes Maria Leal, foi criado um grupo no Centro de Atenção Diária (CAD-Ipub Instituto de Psiquiatria) da Universidade Federal do Rio de Janeiro (UFRJ) e, também, no Centro de Atenção Psicossocial (Caps), esse último mediado por Muñoz ${ }^{10}$.

Tivemos a oportunidade de criar, em parceria com uma Universidade Federal, o primeiro Grupo de Ouvidores de Vozes de Minas Gerais; e, assim introduzir, acompanhar e alimentar esse processo de reflexão e possível construção de um coletivo com potencialidades de maior participação social e busca por novas relações com a sociedade, tendo em vista o respeito à condição de ouvidor e a observância de seus direitos enquanto membro da nossa sociedade. $\mathrm{O}$ grupo foi composto principalmente por usuários do Caps II; e, para a divulgação dos encontros, foram utilizadas postagens em redes sociais, cartazes colocados em dispositivos de saúde e outros locais da cidade, além da participação da coordenadora do projeto em um programa de rádio local a fim de divulgar o grupo enquanto espaço para repensar a experiência de escuta de vozes e o lugar do ouvidor na sociedade.

Após o período inicial de estudos dos estagiários e de divulgação do projeto, ocorreu o primeiro encontro oficial, que agora acontece semanalmente, às terças-feiras, no prédio da Universidade. O grupo 'Ouvi Falá' - como foi nomeado pelos seus integrantes -, tem como base práticas relativas à ideia de horizontalidade e de participação ativa de todos os presentes, seja via discurso oral, seja por meio de desenhos e fotografias, propostos para incentivar os ouvidores a manifestarem suas vozes, sentimentos e aflições.

\section{Metodologia}

Os instrumentos metodológicos utilizados nesta pesquisa foram revisão bibliográfica e observação participante. Por meio da revisão bibliográfica, pode-se aproximar do tema a partir de autores e perspectivas diversas, construindo, assim, um arcabouço teórico para poder analisar o fenômeno proposto. Por intermédio da observação participante, foi possível conhecer a dinâmica dentro do grupo de ouvidores de vozes, seus princípios, práticas e a abordagem de questões que traziam em cena a dimensão social e política daqueles encontros.

A observação participante foi criada pela Escola de Chicago, nos anos 1920, mas foi o antropólogo Malinowski que a tornou mais conhecida em 1922. É então considerado um processo que integra a teoria à prática, implicando, de alguma forma, a transformação 
ou a implementação do meio pesquisado"11. Apresenta, assim, flexibilidade; e, tanto o objeto quanto o objetivo determinam o tipo e a metodologia da pesquisa. Esse tipo de investigação qualitativa consiste na inserção do pesquisador no interior do grupo observado, interagindo e se tornando parte dele, buscando compartilhar o mesmo cotidiano e compreender os sentidos atribuídos pelos membros do grupo. A observação participante ocorreu nas reuniões do grupo de ouvidores 'Ouvi Falá', com frequência de uma vez por semana e duração entre 2 e 3 horas. $O$ grupo contava com uma média de 15 participantes no total, estando presentes cerca de 6 a 12 ouvidores por encontro. Aproximadamente $70 \%$ dos participantes são de classe média baixa, sendo a maioria mulheres, donas de casa e aposentados. A faixa etária varia de 20 a 60 anos, e mais da metade dos ouvidores não possui ensino superior completo. O critério para participação no grupo de ouvidores é a escuta de vozes no presente ou em algum momento da vida do sujeito, assim como a possibilidade de falar a respeito dessa experiência e seguir as diretrizes da Rede Intervoice (expostas acima).

Mantivemos um caderno de anotações específico da pesquisa no qual registramos a emergência de temas relevantes abordados nos encontros em referência a movimentos sociais, assim como tivemos também acesso ao registro dos pontos mais importantes tratados nas reuniões (temáticas, dinâmicas, reflexões e falas) e anotados em um caderno que chamávamos de 'caderninho azul' que circulava entre todos os participantes (um ouvidor ou estagiário a cada encontro). Esse caderno coletivo funcionava como memória e histórico das práticas grupais, sendo os nomes alterados e relatos simplificados para obedecermos às regras do anonimato e de sigilo. Desses registros, foram retiradas as falas dos ouvidores como ilustrativas no artigo em relação às possibilidades de pensarmos o grupo enquanto potência política e movimento social.

A escolha do material bibliográfico para a pesquisa levou em consideração o critério de textos que abordassem as práticas de grupos de ouvidores pertencentes ao Movimento Intervoice, seguindo suas diretrizes e que tivessem relação com a temática social do grupo. Portanto, artigos correspondentes a grupos de ouvidores de vozes não ligados ao Movimento Intervoice não foram incluídos como referências no presente artigo. Conforme debatemos acerca dos movimentos sociais e da emancipação do usuário no campo da saúde mental, exploramos textos que abordavam também os principais preceitos do Intervoice. Conceitos como autonomia, empoderamento, protagonismo, entre outros, foram introduzidos e discutidos com os ouvidores, no intuito de apropriação por parte dos participantes e reflexão sobre suas condições enquanto grupo.

Sendo assim, por meio da revisão bibliográfica e da observação participante, visamos analisar os efeitos dessa dinâmica grupal, dando ênfase àquilo que pudesse aparecer na discussão a partir de um enfoque na relação entre saúde mental e movimento social. Como muitos dos participantes do grupo pesquisado recebiam também algum tipo de tratamento em saúde mental, faz-se importante considerar esses sujeitos não apenas como integrantes do movimento do grupo de ouvidores de vozes, mas também como usuários da rede local. Desse modo, alguns dos textos trabalhados ao longo da pesquisa abordaram problemáticas referentes aos usuários e às possibilidades de maior autonomia e protagonismo dentro das instituições de saúde, buscando entender as repercussões que a participação no grupo poderia trazer à vida de ouvidores que são constantemente atingidos pelas lógicas 'psiquiatrizante' ou 'psicologizante'.

A pesquisa foi aprovada pelo Comitê de Ética e Pesquisa (CEP) da Universidade Federal de São João del-Rei (UFSJ), com o Certificado de Apresentação para Apreciação Ética de número 11967919.8.0000.5151. Parecer CEP sob nº 3.685.183. 


\section{Resultados e discussões}

A partir da observação participante no grupo de ouvidores de vozes 'Ouvi Falá', pudemos abordar de maneira mais aprofundada alguns aspectos referentes ao possível caráter de movimento social que o grupo pode apresentar. De forma espontânea, os participantes se manifestaram e tiveram suas falas colhidas no decorrer dos encontros, trazendo considerações que, de certo modo, refletiam a forma por meio da qual eles concebiam aquela estrutura criada na forma de grupo, a partir de sujeitos e de ações, de modo a fomentar o diálogo aberto sobre suas experiências e as potencialidades em relação às suas vidas e à sociedade. Nos próximos tópicos, iremos apresentar algumas reflexões que tematizam a interação e a articulação grupal como movimento social, abordando temas como empoderamento, autonomia, cidadania e protagonismo.

\section{Grupo de ouvidores de vozes enquanto movimento social}

Ao longo dos encontros, o vínculo entre ouvidores e estagiários foi sendo estabelecido, possibilitando com que experiências nunca relatadas (conforme exposto por alguns dos ouvidores) fossem então compartilhadas, assim como no exemplo de uma das participantes que nos disse "nosso remédio é a fala", ao externalizar um pensamento, emoção ou fato envolvendo grande carga emocional ou psíquica considerada negativa. Pudemos observar que, por meio da externalização no grupo de uma experiência difícil com as vozes com seus pares (demais ouvidores), abria-se a possibilidade, para o sujeito, de estabelecer outro tipo de relação com o dito (ou com o vivido), agregando demais sentidos advindos de experiências semelhantes em termos de intensidade ou de sofrimento.

Relatos quanto à mudança na relação com as vozes foram também observados, como no exemplo de outro ouvidor ao compartilhar no grupo o fato de ter deixado de perceber, ao longo dos encontros, uma das vozes que ouvia como agressiva (de comando), passando a descrevê-la como uma voz positiva, de aconselhamento, mesmo quando ríspida "parecia uma mãe". O que nos leva a considerar a importância do grupo como espaço de reelaboração conjunta de conteúdos psíquicos e de afetos, embora os grupos de ouvidores de vozes não se tratem por definição de grupos terapêuticos.

Ainda que a mudança na relação com as vozes pareça não estar ligada diretamente à questão do movimento social, ela põe em evidência o desencadear de um novo posicionamento diante desse fenômeno. Podemos considerar que tal mudança de posicionamento possa vir a repercutir em um efeito em cadeia, trazendo a consciência da possibilidade de controle do fenômeno, de superação de problemas relacionados com a escuta de vozes e da força do grupo como potencializadora de mudanças individuais e coletivas.

Tendo em vista o conceito de consciência de Vigotski, podemos compreender que a palavra é a transmissora dos reflexos da consciência. Portanto, a fala em contexto de grupo, pode adquirir função importante por possibilitar que a experiência da audição de vozes possa ser compartilhada sem restrições, permitindo que o ouvidor seja capaz de compreendê-la de outras formas, para além dos limites do pensamento médico, psicológico ou social estigmatizante. Como explica Toassa:

A consciência de si implica, pois, numa [sic] relação de alteridade da pessoa para consigo mesma, adquirida através da auto-estimulação produzida pela palavra. $\mathrm{O}$ conhecimento e o reconhecimento são funções da palavra, sendo que uma outra pessoa está sempre presente na sua formulação ${ }^{12(64)}$

Uma das principais finalidades do movimento social enquanto potência política é a transformação da sociedade diante de um ou mais fenômenos ${ }^{3}$. No caso do movimento do grupo de ouvidores de vozes, a mudança diria respeito a um trabalho de aceitação e de reversão da experiência de exclusão social. Compreender e 
promover a ideia de que a audição de vozes não é, por si só, um sinônimo de sintoma de doença mental e que não impede a retomada do sujeito de sua vida cotidiana em um dado momento faz-se fundamental para esse processo de transformação. Pudemos observar que, para ouvidores participantes do grupo, tratava-se da primeira ocasião em que se mantinha com outros ouvidores uma conversa sobre a experiência das vozes, o que nos aponta a importância do grupo para que o ouvidor possa se sentir pertencente a um contexto 'normal', menos adoecido e solitário, dando início a um processo de reinserção social e à retomada dos vínculos.

Foi relatado, durante os encontros dos ouvidores, o fato de que alguns familiares, após terem observado a mudança da relação do ouvidor com as vozes, passaram a compreender de forma mais receptiva essa experiência. Também foi relatado o que compreendemos como uma abertura para o questionamento em relação à medicação e à possibilidade de ter mais consciência sobre o tratamento, como nos exemplos de uma ouvidora ao compartilhar no grupo o fato de ter debatido com seu médico acerca dos remédios prescritos, queixando-se dos efeitos colaterais; e no exemplo de outra ouvidora que nos relatou ter exigido a restrição da presença de estagiários durante a sua consulta.

Temas como confiança, amizade e satisfação pela participação no grupo foram trazidos de forma espontânea por ouvidores, o que nos levou a considerar a sensação de pertencimento no grupo e o processo de identificação entre si enquanto pares. A participação no grupo, ao ser analisada como positiva, ressalta o potencial de transformação que o movimento pode oferecer ao integrar participantes em torno de causas comuns, criando vínculos, promovendo novos discursos e ações em relação às suas prévias condições.

\section{Empoderamento e autonomia}

Compreende-se nesta pesquisa o termo empoderamento (do inglês empowerment) como "valorização do poder contratual dos clientes nas instituições e do seu poder relacional nos contatos interpessoais na sociedade"8(169). Sendo assim, a ideia de empoderamento, no contexto do grupo de ouvidores de vozes, tem por base a proposta de valorização dos integrantes por meio de suas relações interpessoais e da percepção que eles têm de si mesmos, fortalecidos por meio de uma concepção menos adoecedora de si e do fenômeno de escuta das vozes, o que resultaria em um maior poder contratual com a sociedade, familiares e equipe de cuidado.

As chamadas abordagens de empowerment apresentam processos fundantes que embasam também as discussões e as diretrizes da Rede Internacional Intervoice, visando: à reversão de processos de institucionalização e estigmatização por intermédio de críticas aos dispositivos culturais, ambientais e aos serviços que reproduzem o estigma dos usuários; ao apoio e à criação de uma conjuntura que possibilite uma 'vida comum' como a dos demais cidadãos; à estimulação do respeito e mínimo controle e paternalismo em relação aos indivíduos; à estimulação de práticas de empoderamento via

[...] iniciativas de auto-ajuda, suporte mútuo, mudança cultural, defesa dos direitos informal, legal e profissionalizada, de forma individual e coletiva; e a participação efetiva dos usuários nas decisões, nos serviços e agências promotoras de políticas de saúde menta|8(189).

Para o encaminhamento e o fortalecimento de um movimento social, faz-se necessária uma visão estratégica política. Nesse sentido, Vasconcelos $^{8}$ nos aponta algumas possíveis táticas a serem utilizadas em saúde mental: reversão da marginalidade; questionamento dos conceitos empregados na identificação de sujeitos diagnosticados; questionamento do saber médico e da aceitação de formulações estereotipadas; busca por alianças com outros grupos de cidadãos marginalizados e estigmatizados. Segundo o autor, em decorrência das 
questões históricas brasileiras, ao ter em vista a forma como se dá a construção da experiência de adoecimento na América Latina, salta-nos aos olhos a necessidade de um trabalho de base no que se refere à mudança de uma visão psicopatologizante e biomédica da experiência da loucura/doença mental, incentivando o discurso crítico por parte dos pacientes psiquiátricos ${ }^{8}$. Como pontua Bezerra Júnior (2001), citado por Severo e Dimenstein ${ }^{6}$, o usuário deve compreender que a doença ou os sintomas são parte de uma experiência que exige crítica e reflexão, experiência vivida como resultado de diversas determinações que podem ser acessíveis aos seus saberes.

Já o conceito de autonomia é compreendido como "a capacidade do sujeito lidar com sua rede de dependências"13(670), assimilando, assim, que um sujeito autônomo não é um sujeito sozinho no mundo, mas capaz de se compreender e agir sobre si mesmo e sobre os contextos em que se insere, tendo uma rede de relações que o apoie. Dentro do grupo de ouvidores, identificar, conhecer e entender o processo das vozes pode se refletir, para cada um dos integrantes, em um trabalho de construção de autonomia, uma vez que a compreensão do fenômeno permite ao indivíduo um campo maior de ação sobre si mesmo, o encontro com os pares (aqueles que vivenciam a mesma experiência) e um movimento mais confiante na direção do estabelecimento de relações sociais e de redes de apoio.

Um ouvidor, ao compreender o contexto, as condições e as motivações referentes à manifestação de suas vozes, pode então reconhecer a existência da possibilidade de desenvolvimento de certo controle sobre elas, de modo a obter maior poder de negociação. Ao compreender que, dialogando com suas vozes, por vezes, elas podem se tornar mais amenas, dá-se início ao trabalho de enfrentamento, no sentido de favorecer a relação e diminuir os transtornos acarretados pela iminência das vozes. O movimento dos ouvidores de vozes visa, assim, fazer com que o sujeito, ao enfrentar as suas vozes, entendendo-as ao invés de ignorá-las, construa o seu processo de autonomia. Como exemplo observado, temos o caso de uma ouvidora que, ao compreender que poderia interferir em seu processo de escuta de vozes negativas, passou a dar maior atenção às mensagens positivas, não permitindo, dessa forma, a depreciação pelas vozes, focando então na recuperação de sua autoestima e autonomia; assim ela pontua: "acho que elas [as vozes] me respeitam".

\section{Cidadania e protagonismo}

No Brasil, a luta pela cidadania teve destaque em meio aos movimentos sociais ativos em governos autoritários, como o de Vargas e o período da Ditadura Militar, fazendo com que grupos buscassem reconquistar direitos já anteriormente estabelecidos, porém bloqueados com a limitação da Constituição. O fim da década de 1970 foi crucial para que movimentos em prol da saúde fossem pautados de forma mais séria e enérgica, conquistando melhorias, mas, como é analisado por Costa (1986) e retomado por Medeiros e Guimarães ${ }^{14(575)}$ :

[...] as políticas de saúde pública no Brasil não se caracterizaram pela proteção da população contra surtos epidêmicos e doenças parasitárias, tampouco pela recuperação da saúde do comum dos homens, mas sim, pela articulação aos interesses dos grupos dominantes internos ou pela expansão do capitalismo em escala internacional.

Cabe, assim, analisar que a construção da cidadania no campo da saúde no Brasil foi sendo estabelecida de modo a diferenciar os que geram lucro para o Estado dos que não geram, estando entre os últimos os sujeitos tidos como 'loucos'. As internações foram o meio pelo qual seus corpos se tornaram passíveis de controle pelo Estado e pela elite, de modo que o tratamento simulasse uma readaptação ao convencional, buscando encaixar o sujeito afetado por experiências existenciais mais sensíveis a padrões produtivos do capitalismo. 
Mesmo que a audição de vozes não seja vista necessariamente como patologia nos grupos de ouvidores, cabe ressaltar que parte deles recebeu algum diagnóstico ou faz acompanhamento na rede de saúde mental, o que deve ser levado em conta para compreensão da dinâmica dos grupos e da percepção de si mesmos. O que a articulação entre usuários e membros dos grupos de ouvidores de vozes busca desenvolver seria a cidadania dentro do campo da saúde mental, ou seja, nas palavras de Medeiros e Guimarães ${ }^{\mathbf{1 4}(577)}$

[...] o direito de receber assistência adequada, a garantia de participar da sociedade e de não ser pura e simplesmente jogado em depósitos, como ainda é uma realidade brasileira, na sua forma mais brutal, nos grandes hospícios públicos ou, nas formas mais sutis, em clínicas privadas e conveniadas.

De acordo com Passos et al., "ser cidadão é tomar seu lugar em uma sociedade e contribuir para um projeto comum"15(2921), o que nos leva a considerar o contexto do grupo de ouvidores de vozes como um ambiente de promoção de cidadania e de facilitação para que seus membros possam exercê-la na construção de um projeto comum: a luta contra o estigma em relação à experiência de escuta de vozes e a luta contra o apagamento do discurso do sujeito em intenso sofrimento psíquico.

O Movimento Intervoice pode ser compreendido como um movimento revolucionário ao buscar trazer visibilidade à experiência de uma minoria social, legitimando-a e retirando-a da posição de isolamento e constrangimento anteriormente colocada. Por intermédio de um reconhecimento positivo da audição de vozes, acreditamos ser possível formar uma identidade coletiva que supere a identificação advinda de um diagnóstico psiquiátrico. Nessa direção, o Intervoice, enquanto movimento social, procura influenciar as práticas de profissionais da saúde, ouvidores e familiares de maneira crítica quanto aos estigmas, buscando apresentar à comunidade versões menos patologizantes em relação à audição de vozes ${ }^{16}$.

Sendo assim, ao pensarmos na desconstrução do lugar da diferença enquanto anormalidade e na construção de um lugar da diferença enquanto capacidade por meio da perspectiva e das ações do Movimento Intervoice, certo protagonismo pode ser retomado pelo ouvidor ao assumir a posição de sujeito político e ativo em seu tratamento, no grupo e até mesmo ao assumir o controle na relação com suas vozes. A experiência de exclusão social é substituída pela possibilidade de atuar como detentor do saber sobre suas vozes, sobrepondo-se à experiência a um saber institucionalizado. Como afirma Torre e Amarante ${ }^{\mathbf{1 7 ( 8 4 )} \text { : }}$

A construção coletiva do protagonismo requer a saída da condição de usuário-objeto e a criação de formas concretas que produzam um usuário-ator, sujeito político.

\section{Considerações finais}

Enquanto movimento social, pudemos observar que o movimento dos ouvidores de vozes pode apresentar uma nova perspectiva em relação à experiência de ouvir vozes, buscando diluir as barreiras historicamente construídas que separam os saberes de profissionais e de usuários, em uma hierarquia de valores que normalmente leva a subjugar o saber de quem vive a experiência em relação àquele que a contempla como expert. Dessa maneira, tal perspectiva opera no sentido da não sobreposição do saber médico ou psicológico, em relação ao saber da experiência, já que o sujeito que vivencia a audição de vozes é quem deve interpretá-la e ter a expertise da situação.

Conforme pudemos observar, o Hearing Voices Movement, tratando-se de um movimento composto por indivíduos e vozes de vários países, tem a pluralidade como característica determinante, prezando pela compreensão das vozes por meio de diversas versões, sem imposições ou hierarquias de saberes, 
*Orcid (Open Researcher and Contributor ID). propondo um trabalho constante de elaboração do próprio ouvidor com seus pares, tendo como base a empatia e o respeito ${ }^{18}$. Ao seguir essas diretrizes, o grupo pode se estabelecer como alicerce para os ouvidores, não apenas nos processos individuais de recuperação, mas na sustentação coletiva enquanto movimento social, na busca por representatividade e na manutenção de uma forte e coesa rede de apoio e cuidado entre seus integrantes.

Devido ao fato de as reuniões terem sido iniciadas no contexto universitário - e, também, da constante presença de estudantes e de profissionais e professores da área da saúde-, pudemos observar, por consequência, que determinados participantes ouvidores apresentavam (ou reproduziam), a princípio, certa dependência (posição de passividade) em relação às iniciativas propostas no grupo, uma vez que, de início, eram os estagiários ou profissionais a evocar temas e propostas de discussões, assim como as dinâmicas. No entanto, passado mais de um ano da formação do grupo, foi possível observar o desenvolvimento paulatino de um senso de pertencimento ao grupo por parte dos ouvidores, com a participação assídua na escolha dos temas, problematizações e dinâmicas a serem oferecidas nos encontros, com a frequência nas reuniões de ouvidores mesmo com a ausência dos estagiários ou da coordenadora do projeto, dando-nos indícios de um processo de autonomia dos participantes em relação aos profissionais envolvidos. Cabe destacar que, no decorrer do processo grupal de criação de vínculos e estabelecimento de ações, os próprios ouvidores passaram também a realizar conferências para profissionais da área da saúde mental em eventos no estado de Minas Gerais, com estagiários ou com coordenadora do projeto, assim como seminários sobre a experiência de ouvir vozes e sobre a importância dos grupos de ouvidores de vozes para alunos de graduação em Psicologia e Medicina.

Ao retomar os conceitos de empoderamento, autonomia, cidadania e protagonismo no campo da saúde mental e, especialmente, no que diz respeito aos ouvidores de vozes, pudemos observar que as práticas norteadoras do Movimento Intervoice, assim como as diretrizes seguidas pelos grupos de auto e mútua ajuda, auxiliam na criação de espaços de reflexão e permitem que os participantes dos grupos assumam certas ações e posicionamentos que não teriam sido viabilizados antes da participação nos grupos, uma vez encontrando-se solitários na experiência de audição de vozes. Podemos, assim, considerar como uma possível mudança de posicionamento advinda da participação nos grupos a não recepção passiva de concepções em relação a seus estados de saúde e a participação ativa na escolha e na condução de seus tratamentos.

Consideramos, enfim, que o movimento da Rede Internacional Intervoice (com pesquisa, formação e criação de grupos de ouvidores de vozes) pode, sim, assumir um papel relevante enquanto movimento social, uma vez que orienta suas ações e discursos na busca pelos direitos políticos e civis de seus integrantes, no estatuto de normalidade para o sujeito ouvidor, na possibilidade de cidadania e manutenção da circulação social do ouvidor, na possibilidade de seguir suas vidas em companhia de suas vozes, assim como no trabalho em prol da dissolução dos estigmas referentes à loucura e na transformação em relação à compreensão da experiência sensível e intensa da escuta de vozes.

\section{Colaboradoras}

Trevisan JVS (0000-0001-7704-5184)* contribuiu para a concepção, o planejamento, a análise e a interpretação dos dados; revisão crítica do conteúdo; e aprovação da versão final do manuscrito. Baroni DPM (0000-00015210-0650)* contribuiu para a concepção, o planejamento, a análise e a interpretação dos dados; revisão crítica do conteúdo; e aprovação da versão final do manuscrito. 


\section{Referências}

1. Baker P. The Voice Inside: a practical guide for and about people who hear voices. United Kingdom: P\&P Press; 2009.

2. Gohn MG. Abordagens teóricas no estudo dos movimentos sociais na América Latina. Cad. CRH [internet]. 2008 [acesso em 2019 abr 14]; 21(54):439-455. Disponível em: https://doi.org/10.1590/S010349792008000300003.

3. Lüchmann LHH, Rodrigues J. O movimento antimanicomial no Brasil. Ciênc. Saúde Colet. 2007; 12(2):399407.

4. Amarante P. Loucos pela vida: a trajetória da reforma psiquiátrica no Brasil. Rio de Janeiro: Fiocruz; 1995.

5. Correia LC. O movimento antimanicomial: movimento social de luta pela garantia e defesa dos direitos humanos. Prim Facie. 2006; 5(8):83-97.

6. Severo AKS, Dimenstein M. O diagnóstico psiquiátrico e a produção de vida em serviços de saúde mental. Estud. psicol. (Natal). 2009; 14(1):59-67.

7. Bien C, Reis GC. The hearing voices movement: mental health advocacy and Recovery. CBSM. 2017; 9(21):7988.

8. Vasconcelos EM. Reinvenção da cidadania, empowerment no campo da saúde mental e estratégia política no movimento de usuários. In: Amarante P, organizador. Ensaios: subjetividade, saúde mental, sociedade. Rio de Janeiro: Fiocruz; 2000. p. 169-194.

9. Intervoice \& The Hearing Voices Movement: Values \& Vision [internet]. London: The International Hearing Voices Network; c. 2020 [acesso em 2020 ago 9]. Disponível em: http://www.intervoiceonline.org/ about-intervoice/values-vision.

10. Coimbra VCC, Bretanha AF, Rodrigues CGS. Sobre os caminhos do primeiro grupo de ouvidores de vozes no Brasil. J. nurs. health. 2018; 8(esp):e188421.
11. Queiroz DT, Vall J, Souza AMA, et al. Observação participante na pesquisa qualitativa: conceitos e aplicações na área da saúde. Rev. Enferm. UERJ. 2007;15(2):276-283.

12. Toassa G. Conceito de consciência em Vigotski. Psic. USP [internet]. 2006 [acesso em 2020 jan 18]; 17(2):5983. Disponível em: https://doi.org/10.1590/S010365642006000200004 .

13. Onoko Campos RT, Campos GWS. Co-construção de autonomia: o sujeito em questão. In: Campos GWS, Minayo MCS, Akerman M, et al., organizadores. Tratado de Saúde coletiva. Rio de Janeiro: Hucitec/Fiocruz; 2006. p. 669-688

14. Medeiros SM, Guimarães J. Cidadania e saúde mental no Brasil: contribuição ao debate. Ciênc. Saúde Colet. 2002; 7(3):571-579.

15. Passos E, Otanari TMC, Emerich B, et al. O Comitê Cidadão como estratégia cogestiva em uma pesquisa participativa no campo da saúde mental. Ciênc. Saúde Colet. 2013; 18(10):2919-2928.

16. Longden E, Corstens D, Dillon J. Recovery, discovery and revolution: The work of Intervoice and the hearing voices movement. In: Coles S, Keenan S, Diamond B, editores. Madness contested: Power and practice. Monmouth: PCCS Books; 2013.

17. Torre EHG, Amarante P. Protagonismo e subjetividade: a construção coletiva no campo da saúde mental. Ciênc. Saúde Colet. 2001; 6(1):73-85.

18. Intervoice \& The Hearing Voices Movement [internet]. London: The International Hearing Voices Network; c. 2020 [acesso em 2020 jan 18]. Disponível em: https://www.intervoiceonline.org/about-intervoice.

Recebido em 29/02/2020

Aprovado em 18/08/2020

Conflito de interesses: inexistente

Suporte financeiro: não houve 